\title{
US Congressional committee rejects Carter compromise on fast breeder programme
}

PRESIDENT Carter may again be required to use his power of veto in his attempts to terminate the controversial Liquid Metal Fast Breeder Reactor Project at Clinch River near Oak Ridge in Tennessee.

This follows last week's rejection by a key Congress committee of a compromise formula offered by the Department of Energy that would have substituted a long-term design project of a larger breeder reactor, including the study and evaluation of alternative fuel cycles.

The president has, since his campaigning days in 1976, consistently opposed the Clinch River project. However it has been equally strongly supported both by Congress and by the nuclear industry, which argues that the construction and licensing of the reactor is the necessary and logical next step in the development of a commercial fast breeder system.

Last autumn President Carter vetoed an authorisation bill which had been approved by Congress and included moncy to continue the Clinch River project, although he later signed a supplementary appropriations bill allocating $\$ 80$ million for the project, largely because the bill gave him his way on another presidential target, the B-1 bomber.

In his proposed research and development budget for the Department of Energy for 1979, which was presented to Congress in January of this ycar, the President recommended that the Clinch River budget be reduced to $\$ 13.4$ million and that this money be used to terminate the project.

The fossil and nuclear energy subcommittee of the House Committee on Science and Technology, however, which contains a number of nuclear supporters, revised the president's request and inserted provision for $\$ 173$ million to be spent on the project, not necessarily for its termination.

In an cffort to forestall what seemed an inevitable extension of the conflict between Congress and the adminis- tration, Dr James R. Schlesinger, Secretary for Energy, proposed a compromise formula last month in which, in return for Congress' acceptance of the termination of the project, the administration would agree to initiate design studies for a larger 650-900 MW fast breeder reactor.

They would include a study of alternative configurations both of the uranium/plutonium cycle and the thorium/uranium cycle.

When the DoE's authorisation bill came before the full Committee on Science and Technology last week, Representative Walter Flowers (Dem.Ala.), chairman of the subcommittee which had previously recommended funding for the Clinch River project, offered an amendment which was broadly in line with the administration's proposed compromise.

However in spite of the support of both those committee members who agreed with the president's desire to terminate the project, and othersincluding the chairman, Olin Teague-who although supporting the project, were prepared to accept the compromise as the best solution that could be expected in the circumstances, the amendment was defeated by the close margin of 20 votes to 18 .

In its place the committee accepted by 25 votes to 14 an alternative amendment offered by Mrs Marilyn L. Lloyd who represents the district of Tennessee in which the breeder would be built, authorising the expenditure of $\$ 35$ million on the new study proposed by the Department of Energy, but leaving standing the subcommittee's proposal that work on Clinch River be continued.

In the long run, the committee's refusal to authorise furds to terminate the project is unlikely to have much effect. Dr Schlesinger made it plain, in offering his compromise, that the administration considers Clinch River is as good as dead; and in spite of the recent publicity given to the Comptroller General's apparent statement in a letter that Carter's efforts to terminate the project were illegal, the president's supporters point out that elsewhere in the letter it was admitted that provisions in the contract did exist for it to be terminated unilaterally, although this could involve drawn-out litigation.

Although the president has been consistent in his opposition to the CRFBR--which has already involved the joint investment by Congress and private utility companies of about $\$ 800$ million and has reached the components testing stage--his argument has shifted.

Initially Carter's main, and widelypublicised, argument was the threat of the further proliferation of nuclear weapons implied by the use of plutonium in the fast breeder cycle.

Over the past year, however, partly because of a lack of success in convincing other countries of the logic of the US stand, and partly because of internal pressures and criticism, the proliferation argument has figured less and less prominently. In its place the debate has shifted to the size and shape of future energy demand.

The utility companies and the nuclear construction industry, following carefully designed plans for continuous expansion in which much capital has been invested in the promise of eventual returns, have argued that in order to meet projected energy needs, commercial orders for fast breeders must be placed by 1990) at latest. Clinch River, as both argued with a single voice before the energy subcommittee two weeks ago, is the necessary next step in the "orderly development" of a fast breeder programme.

President Carter, on the other hand, armed with declining projections of future population, the development of alternative energy technologies, and other leaves taken from the "soft technologists", book, has, with the Department of Energy, been able to argue a case that fast breeders will not be required before 2200 .

It is the space between the forecasts

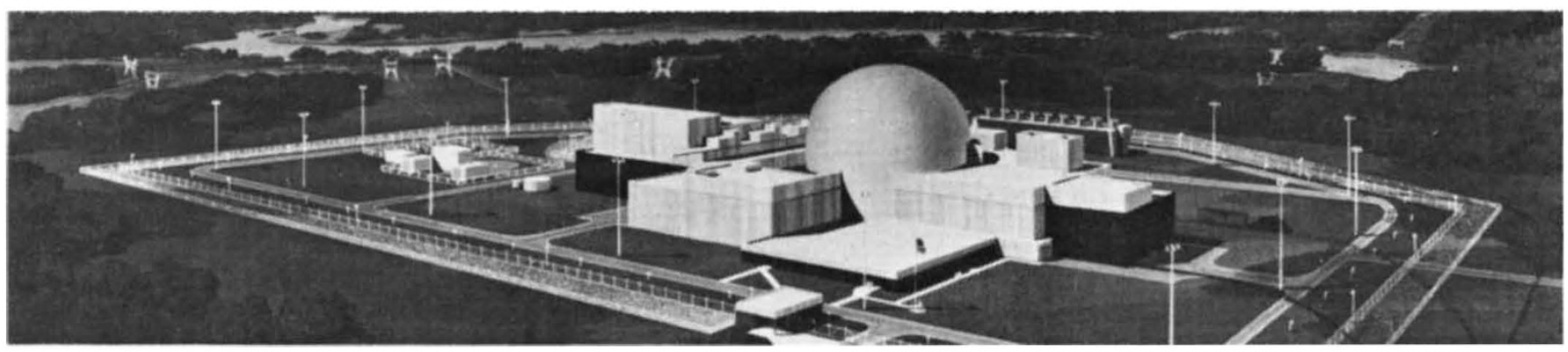


of the nuclear establishment and its critics that has provided Carter with room for political maneouvring. And to give in at this point on the Clinch River issue would do little to help a presidential image already tarnished by an apparently equivocal stand on issues such as the neutron bomb.

The compromise solution has, admittedly, not pleased the environmentalist lobby, who point out that it merely reinforces a commitment to a nuclear future, and that it is, in the words of James M. Cunie of New Directions, "a de facto re-establishment of a commitment to move forward with commercial demonstration of the breeder reactor."

\section{Little renewable}

RENEWABLE sources of energy-wind, wave, sun, geothermal heat and the like-are, you may be surprised to learn, taken seriously at the United Kingdom Atomic Energy Authority, Harwell. Dr Freddie Clarke, Research Director (Energy), who is responsible for the non-nuclear energy programmes of the UKAEA, delivered his assessment of alternative energy futures-broadly a thumbs down until next century-to a one-day meeting on energy in London last week. The meeting was organised by the National Federation of Women's Institutes, and was opened by the Prime Minister.

What could we consider to be a "substantial" contribution to UK energy supply by the year 2000? We now used 330 million tonnes of coal equivalent, Dr Clarke said, of which some 200 mtce were in oil and gasforms which might be scarce and more expensive "sometime after 2000"

Official forecasts put demand at 500 mtce by 2000 . The possibilities for meeting this increase. Dr Clarke said, are conservation, coal. nuclear, and renewable sources. But no contribution of less than 50 mtce per year could be considered substantial, he thought, and he set out to measure the renewable potential against this yardstick.

The conclusion he reached was that by 2000 there would only be a "minor", contribution from renewable sources of energy. But "somewhere in the world" they are economical here and now. Only if there were no technical setbacks in the development of renewable sources (an unlikely event), might we reach take-off-application in the UK on a substantial scale.

Some $30 \%$ of the UK's energy is for low temperature space heating, which makes geothermal heat look a good bet. The temperature of rocks increases at about $30^{\circ} \mathrm{C}$ per $\mathrm{km}$, and some deep sedimentary rocks are
The environmentalists, having previously supported Carter's efforts to terminate Clinch River, have urged that the compromise be rejected by Congress - which, if nothing else, will make it easier for the nuclear supporters who oppose the environmentalists to accept it. But even the science committee vote, plus the likelihood that the appropriations committees in both the House and the Senate will continue to support the project, does not make a presidential veto inevitable.

Two alternatives remain. One is that Democrats in Congress, aware that there is little chance of raising the twothirds majority needed to over-ride a presidential veto, and unwilling to embarrass Carter-particularly in an election year-by further confrontation, will introduce an amendment along the lines of that proposed by Mr Flowers in debate on the DoE bill.

The other possibility is that the Senate Committee on Energy and Natural Resources, which meets soon to decide its position on the president's budgetary request, will accept the Schelsinger compromise, thus opening the way for it to be debated between Senate and House in conference.

If all else fails, and both houses reject the compromise formula, another presidential veto seems inevitable.

David Dickson

\section{energy until next century}

penetrated by water, which can be drawn up to provide heating. A block of flats in Paris already receives 70\% of its heat from such a source. In the UK, the midland valley of Scotland, the East Yorkshire-Lincolnshire basin, and the Hampshire basin are the best sources.

But this form of energy is not easily transported, and we have to see if demand is where the water is. The match in the UK is not very good, and Clarke could see little more than 2 to 3 mtce from this source by 2000 - the figure envisaged in France.

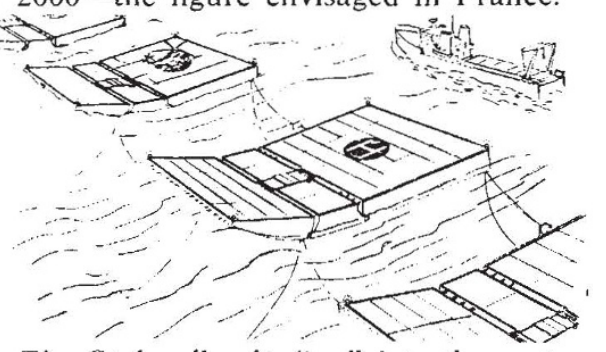
The Cockerell raft: "well into the next century" before wavepower makes a substantial contribution

The "hot rock" technique, on the other hand, in which dry rocks are fragmented at 2 to $3 \mathrm{~km}$ depth and cold water pumped down to heat up, could yield several times the 2 to 3 mtce figure. Early results from a test site at Los Alamos "look encouraging" said Clarke.

Household solar energy, used for water heating, cost $£ 600$ to $£ 700$ to fit. At a current return of $£ 20$ to $£ 40$ per year, it was not yet economicalthough the Government was researching ways to reduce the capital cost. It might pay by the 1980 s. But here was a problem for all energy accounting: we don't know how easily the new technologies can be developed. Also, solar energy came mainly in the summer, and we need our heat mostly in the winter. Yet it was possible, said Clark, if everything went well, that solar energy could contribute 50 to 100 mtce by 2000 .

The remaining renewable sources would be most likely to generate electricity rather than direct heat. A 50-metre windmill (about as high as an electricity pylon) could be economical now. But the interaction of an erratically turning mill and the national supply grid-into which it would feed-might cause problems. And the most efficient land-based sites for the mills would be on coastal hills in some of the most unspoilt parts of the country. The mills could be based off-shorc, but would be more difficult to engineer there. On-shore, using the best sites, they could provide 6 mtce per year, Dr Clarke estimated. At sea this might rise to $20 \mathrm{mtce}$ per year.

Wave power is the "most promising" renewable source in government eyes, with 100 mtce per year by 2000 "not inconceivable". But this system faces the greatest engineering difficulties.

The Department of Energy began a study of wave power. "Something struck me greatly when I saw artists' impressions of the full-scale machines" said Clarke. "It's the scale of the things". Clarke showed pictures of projects such as the "Salter ducks" and the "Cockerell rafts". "One element of these devices could contain this hall (the Central Hall, Westminster)" said Clarke. And they must run reliably even in the roughest part of the year. They represented "a new dimension in engineering" which was going to take time. It would be well into the next century before they make a big contribution, said Clarke.

Finally, tidal power, even using the best sites in the UK, can provide no more than 10 mtce per year and so cannot be a substantial contributor. It is also at present uneconomic.

Robert Walgate 